\title{
PKM Pengembangan Usaha IRT Jamu Tradisional di Desa Tibubiu Tabanan
}

\author{
${ }^{1}$ Ni Wayan Cahya Ayu Pratami , ${ }^{2}$ Ni Nyoman Muryatini, ${ }^{3}$ Ni Putu Linda Santiari, \\ ${ }^{4}$ I Gede Surya Rahayuda, ${ }^{5}$ I Nyoman Sunda \\ INSTITUT TEKNOLOGI DAN BISNIS STIKOM BALI ${ }^{1,2,3,4,5}$ \\ *Email: ayu_pratami@stikom-bali.ac.id 1 nyoman_muryatini@stikom-bali.ac.id² linda_santiari@stikom- \\ bali.ac.id ${ }^{3}$ surya_rahayuda@ stikom-bali.ac.id ${ }^{4}$ nyomansunda12345@gmail.com ${ }^{5}$
}

\begin{abstract}
ABSTRAK
Jamu merupakan obat tradisional khas Indonesia. Terbuat dari bahan-bahan alami berupa tumbuhan seperti rimpang (akar-akaran), daun-daunan, kulit batang dan buah. Jamu sudah menjadi obat herbal secara turun temurun. Salah satu usaha industri rumah tangga yang memproduksi jamu tradisional adalah industri rumah tangga jamu Jeng Innez yang terletak di Desa Tibubiu, Kerambitan, Kabupaten Tabanan, Bali. Industri rumah tangga ini berdiri sejak tahun 2012, pemilik usaha ini adalah Ibu Istyaningsih. Dalam produksi jamu ini Ibu Istyaningsih dibantu oleh suaminya dan seorang karyawan. Usaha ini berawal dari keinginan pemilik usaha untuk melestarikan warisan leluhurnya yang memiliki kemampuan meracik jamu dan produk jamu yang dihasilkan oleh Ibu Istyaningsih ini memiliki cita rasa yang nikmat dan segar karena dibuat dari bahan alami dan berkualitas. Beberapa produk jamu yang dihasilkan adalah jamu kunyit asam, jamu beras kencur, jamu sari rapet, jamu kuat dan lainnya. Dari hasil diskusi diketahui permasalahan utama adalah keterbatasan alat produksi, kemasan tidak menarik serta kurangnya strategi promosi dan pemasaran produknya. Prosedur kerja dari kegiatan pengabdian ini terdapat tiga bentuk kerja utama yaitu sosialisasi kegiatan kemudian peningkatan kualitas dan jumlah produksi. Hasil dari pengabdian terjadi peningkatan produksi sehingga pendapatan juga meningkat sebesar $335 \%$ dari target awal sebesar $100 \%$. Desain kemasan dan labelling yang menarik serta teknologi pemasaran melalui media online memperluas pangsa pasar dari industri ini.
\end{abstract}

Kata kunci : pengabdian, jamu, Tabanan

\section{ABSTRACT}

Jamu is a traditional Indonesian medicine made of natural ingredients such as rhizomes (roots), leaves, bark and fruit. Jamu has become a herbal medicine for generations. One of the home industry businesses that produce traditional herbal medicine is Jeng Innez herbal medicine home industry located in Tibubiu Village, Kerambitan, Tabanan Regency, Bali. This home industry was founded in 2012, the owner of this business is Istyaningsih. In the production of this herbal medicine, Istyaningsih was assisted by her husband and an employee. This business started from the desire of the business owner to preserve her ancestral heritage and it has the ability to mix herbs and herbal products produced by Mrs. Istyaningsih, this jamu has a delicious and fresh taste because it is made of natural ingredients and quality. Some herbal medicine products produced are turmeric acid, saffron- 
colored rice herbal medicine, sari rapet herbs, strong herbs and others. From the results of the discussion, it is known that the main problems are the limited production equipment, unattractive packaging, lack of product promotion and marketing strategies. There are three main work procedures of the service activities, namely the socialization of activities and then increasing the quality and quantity of production. As a result of community service, production increased so that revenue also increased by $335 \%$ from the initial target of 100 $\%$. Attractive packaging, labeling design and marketing technology through online media expand the market share of this industry.

Key words: community service, jamu, Tabanan

\section{PENDAHULUAN}

Desa Tibubiu merupakan salah satu dari 15 desa di Kecamatan Kerambitan Kabupaten Tabanan Provinsi Bali. Batas Desa Tibubiu disebelah utara adalah Desa Belumbang, sebelah selatan adalah Samudera Indonesia, sebelah timur adalah Tukad Yeh Lating dan sebelah barat adalah Tukad Yeh Ho. Jadi desa ini berada paling pelosok yang langsung berbatasan dengan Samudera Indonesai. Kondisi geografis wilayah Desa Tibubiu merupakan dataran rendah. Usaha industri rumah tangga di desa ini cukup banyak tapi rata-rata belum maksimal dalam manajemen produksinya. Salah satu usaha industri rumah tangga yang terdapat di Desa Tibubiu adalah jamu tradisional Jeng Innez. Jamu tradisional yang dimiliki oleh Ibu Istyaningsih adalah usaha yang berdiri sejak tahun 2012. Ibu Istyaningsih dibantu oleh suami dan seorang karyawan dalam proses produksi. Usaha ini berawal dari keinginan dari Ibu Istyaningsih untuk melestarikan warisan leluhurnya yang memiliki kemampuan untuk meracik jamu. Jamu racikan Ibu Istyaningsih ini memiliki citarasa yang nikmat dan segar karena dibuat dari bahan-bahan alami yang berkualitas. Sebagaimana diketahui bahwa jamu tradisional memiliki manfaat yang tidak kalah dibandingkan dengan obatobatan, sehingga layak dijadikan produk unggulan untuk program pengabdian.

Industri rumah tangga jamu tradisional Jeng Innez dalam memproduksi jamu masih menggunakan cara tradisional.
Proses menumbuk rempah-rempahan masih menggunakan lesung, sehingga dalam hal jumlah produksi kurang maksimal, setiap hari hanya memproduksi 9 (sembilan) liter jamu. Pengemasan produk juga menggunakan botol minuman bekas, sehingga kurang menarik daya beli konsumen. Permasalahan utama dari industri rumah tangga ini adalah mengenai proses produksi, promosi dan pemasaran. Saat ini kemasan produk tidak memiliki labelling. Hal ini akibat kurangnya pengetahuan dalam strategi promosi dan pemasaran. Dengan labelling dan desain kemasan yang menarik dapat menjadi salah satu faktor yang sangat berpengaruh terhadap daya beli konsumen. Kemudian pemasaran jamu ini hanya menjangkau masyarakat sekitar, sehingga perlu dilakukan strategi pemasaran yang dapat menjangkau wilayah yang lebih luas lagi. Sehingga hal tersebut dapat berpengaruh terhadap pendapatan secara langsung.

Kondisi alat produksi dan kemasan produk mitra pengabdian ditunjukkan pada gambar 1 dan 2 dibawah ini :

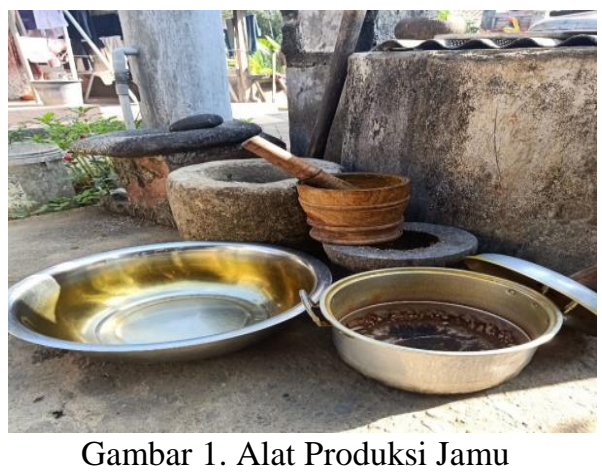




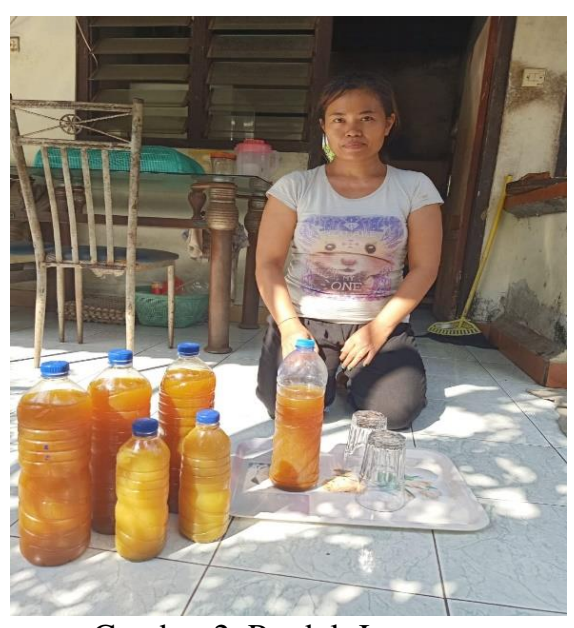

Gambar 2. Produk Jamu

\section{RUMUSAN MASALAH}

Berdasarkan hasil analisa pada analisis situasi diatas, maka dapat ditarik beberapa permasalahan yang dihadapi oleh mitra adalah sebagai berikut :

1. Untuk produksi dalam jumlah besar, mitra belum dapat menangani karena keterbatasan dari alat produksi yang dimiliki yaitu hanya menggunakan lesung, sehingga dibutuhkan mesin penggiling rempah untuk meningkatkan hasil produksi.

2. Kemasan produk jamu tradisional belum memiliki labelling kemasan sehingga belum mampu menarik daya beli konsumen.

3. Hasil produksi hanya dipasarkan di masyarakat sekitar dan pasar tradisional karena kurangnya berintegrasi dengan teknologi untuk media promosi.

Solusi yang dilakukan tim pengabdian untuk permasalahan mitra antara lain :

1. Pemberian bantuan berupa mesin penggiling rempah agar jumlah produksi lebih banyak dan lebih cepat.

2. Memberikan penyuluhan tentang manfaat dan tujuan labelling serta mengadakan pelatihan untuk memberi label kemasan yang berisi identitas, nama usaha dan no telephone mitra pada produk.
3. Memberikan pelatihan mengenai media pemasaran online untuk membantu pemasaran yang lebih luas.

\section{METODE}

Metode yang digunakan pada pengabdian ini adalah berupa pelatihan dan penyuluhan kepada mitra . Penyuluhan labelling dan pelatihan pemberian label pada kemasan ini dilakukan untuk proses pemasaran agar bisa mengenalkan ciri produk mitra. Label adalah bagian kemasan yang berisi informasi tertulis dan dibubuhkan diatas atau bersama dengan kemasan itu, yang menerangkan hal ikhwal produk (Philip Kotler : 2009). Paling tidak sebuah label menyebutkan nama produk atau merk. Saat ini informasi yang dicantumkan dalam label sudah sangat mengalami kemajuan, sehingga beberapa penulis membedakan fungsi label menjadi label yang menyebutkan produk, label yang memberikan tingkatan produk, label yang menggambarkan produk dan label yang mempromosikan produk. Secara garis besar terdapat tiga macam label (Marinus : 2002), yaitu :

1. Brand label, yaitu nama merk yang diberikan pada produk atau dicantumkan pada kemasan.

2. Descriptive label, atau informative label adalah label yang memberikan informasi objektif mengenai penggunaan konstruksi atau pembuatan, perawatan atau perhatian dan kinerja produk serta karakteristik yang berhubungan dengan produk.

3. Grade label, yaitu label yang mengidentifikasi penilaian kualitas produk (product's judged quality) dengan tulisan atau kata-kata.

Pelatihan media promosi pemasaran online juga diberikan kepada mitra agar dapat memasarkan produk lebih luas lagi. Pelatihan yang diberikan berupa pelatihan menggunakan media sosial (facebook, WA dan Instagram) untuk memasarkan produknya melalui e-marketing. Keller dan Kotler memberikan definisi e-marketing 
adalah upaya sebuah perusahaan untuk menginformasikan, mengkomunikasikan, mempromosikan, dan menjual produk dan jasanya melalui media internet (Philip Kotler, Kevin Lane Keller : 2007).

Berdasarkan permasalahan mitra yang menjadi prioritas maka terdapat beberapa kegiatan yang akan dilaksanakan untuk menangani permasalahan tersebut, yaitu :

1. Sosialisasi kegiatan kepada mitra . Pada kegiatan ini akan disampaikan beberapa pengarahan tentang informasi mengenai latar belakang kegiatan, target dan tujuan dari kegiatan pengabdian. Kegiatan ini juga dilakukan pencatatan data dan informasi proses produksi mitra serta dokumentasi.

2. Kegiatan setelah sosialisasi adalah melakukan pemantauan kegiatan produksi mitra. Pada tahap pemantauan kegiatan, juga dilakukan peningkatan kuantitas produksi dengan menambahkan alat produksi yaitu mesin penggiling rempah sehingga menghasilkan produk dengan kapasitas yang lebih besar.

3. Kegiatan selanjutnya adalah penyuluhan dan pelatihan labelling kemasan. Penyuluhan labelling dilakukan untuk proses pemasaran dan untuk mengenalkan ciri khas produk mitra. Kegiatan ini akan dilakukan oleh Ni Wayan Cahya Ayu Pratami, Ni Nyoman Muryatini dan dibantu mahasiswa I Nyoman Sunda.

4. Pelatihan media promosi pemasaran berupa pelatihan menggunakan media sosial (Facebook, WA dan Instragram). Kegiatan ini diberikan oleh Ni Putu Linda Santiari, I Gede Surya Rahayuda dan dibantu mahasiswa I Nyoman Sunda.

5. Evaluasi kegiatan pada prosedur kerja akan dilakukan setelah pelatihan media promosi pemasaran yang merupakan tahap akhir prosedur kerja. Prosedur kerja pada tahap ini dilakukan untuk mengetahui keberhasilan dari kegiatan yang dilakukan oleh tim pengabdian yaitu Ni Wayan Cahya Ayu Pratami, Ni
Nyoman Muryatini, Ni Putu Linda Santiari, I Gede Surya Rahayuda dan dibantu mahasiswa I Nyoman Sunda.

\section{PEMBAHASAN}

Kegiatan pengabdian ini dilakukan dalam tiga tahap dengan persiapan yang dilakukan selama dua minggu. Kegiatan ini dimulai dari sosialisasi ke tempat mitra industri rumah tangga Jamu Jeng Innez, pemberian alat produksi penggilingan rempah, penyuluhan dan pelatihan labelling kemasan, serta evaluasi kegiatan. Dari seluruh kegiatan yang telah dilakukan oleh mitra dan tim pengabdian ini dapat disimpulkan bahwa kegiatan berjalan dengan baik. Mitra dan peserta sangat antusias dalam kegiatan pengabdian yang telah dilaksanakan. Berikut tahapan kegiatan pengabdian yang telah dilakukan:

1. Sosialisasi dilakukan pada mitra, dengan menyampaikan informasiinformasi mengenai latar belakang, target, sasaran dan tujuan. Pada gambar 3 dibawah ini adalah kegiatan sosialisasi :

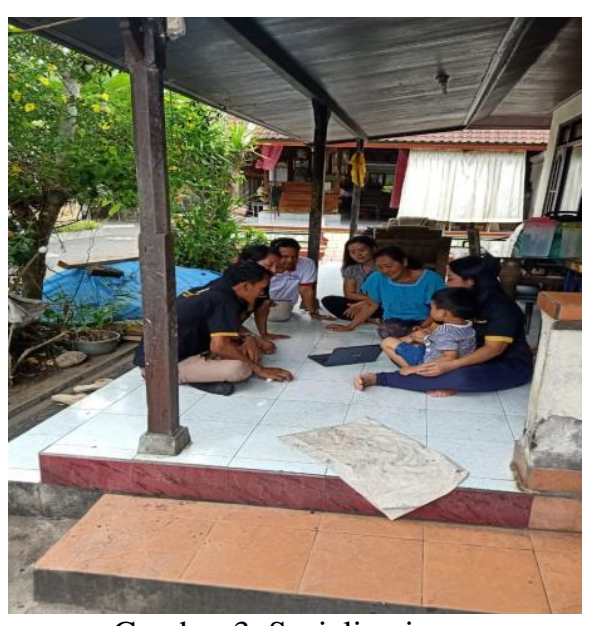

Gambar 3. Sosialisasi

2. Pemberian bantuan alat produksi. Alat produksi yang diberikan adalah alat penggilingan rempah Gasoline Engine Yamaoke YX 1605.5 HP. Dengan pemberian alat tersebut diharapkan dapat meningkatkan jumlah produksi dibanding sebelumnya hanya menggunakan lesung dengan produksi 
terbatas. Gambar penyerahan alat produksi pada gambar 4 dibawah ini:

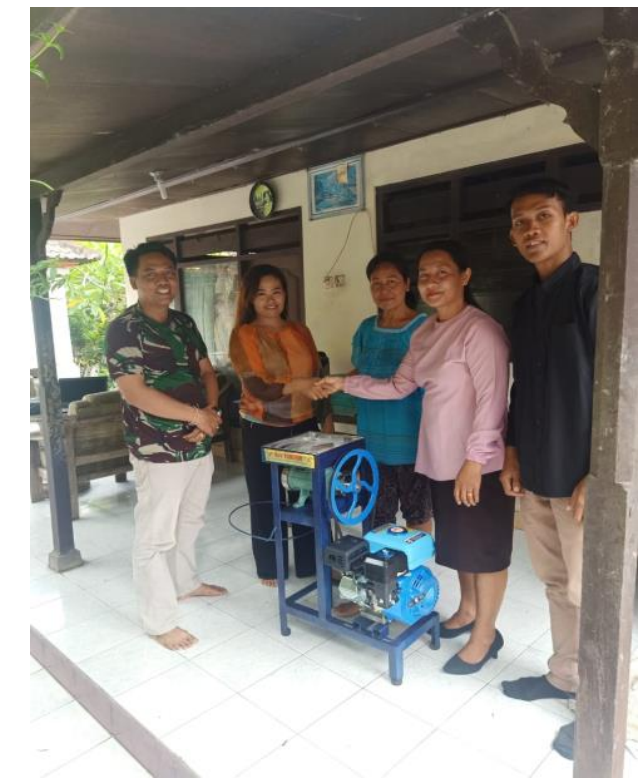

Gambar 4.Penyerahan Alat Produksi

3. Penyuluhan dan pelatihan labelling kemasan diikuti oleh mitra dengan sangat antusias. Kemudian pelatihan dalam menggunakan media online (facebook,WA dan Instagram) juga mereka sangat antusias. Kegiatan ini diikuti oleh tiga orang peserta dengan kriteria umur diatas 17 tahun, jenis kelamin pria dan wanita, status pekerjaan adalah pemilik dan karyawan. Kegiatan yang dilakukan dalam penyuluhan dan pelatihan ini adalah mensosialisasikan manfaat dan kegunaan labelling kemasan. Penggunaan labelling kemasan merupakan strategi dalam pemasaran untuk menarik daya beli konsumen (Tjiptono : 2008). Tim pengabdian juga menjelaskan manfaat dari strategi pemasaran online untuk memperluas pangsa pasar melalui media online (facebook, WA dan Instagram). Seperti pada eBay yang mengalami perkembangan pesat melalui komunikasi dan penerapan eCRM dalam membangun dan mengelola hubungan dengan pelanggan (Kalyanam, Kirthi, dan Shelby Mclntyre : 2002). Harapan tim pengabdian adalah dengan memberikan penyuluhan dan pelatihan ini bisa membantu kualitas dan kuantitas produk serta memperluas pangsa pasar online. Gambar penyuluhan dan pelatihan serta hasil dari pelatihan pada pengemasan produk dengan label pada gambar 5,6,7 dan 8 dibawah ini :

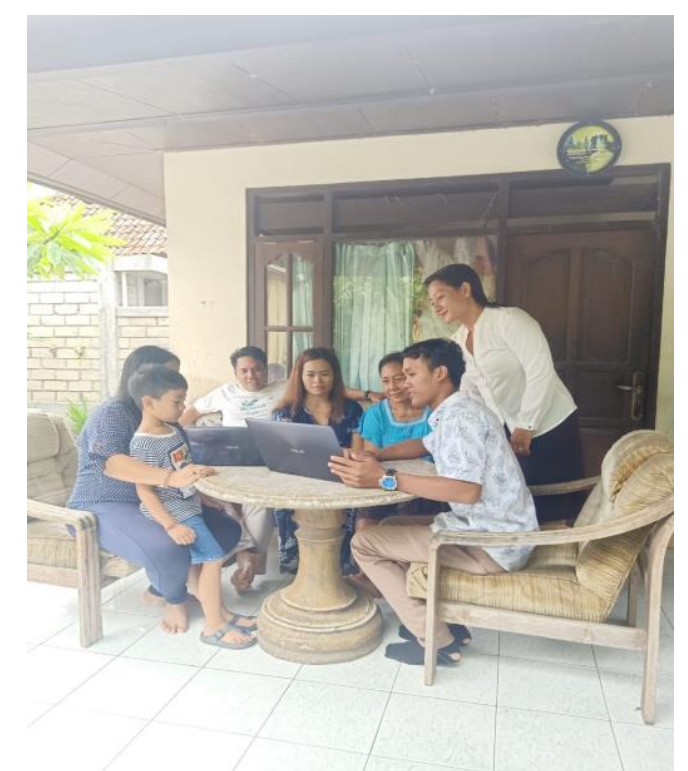

Gambar 5. Penyuluhan dan Pelatihan

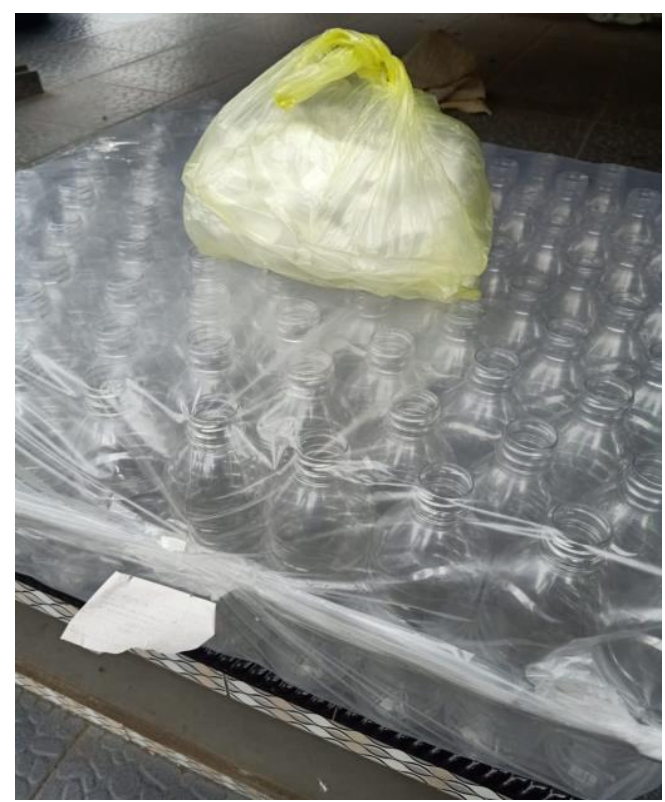

Gambar 6. Botol Kemasan 


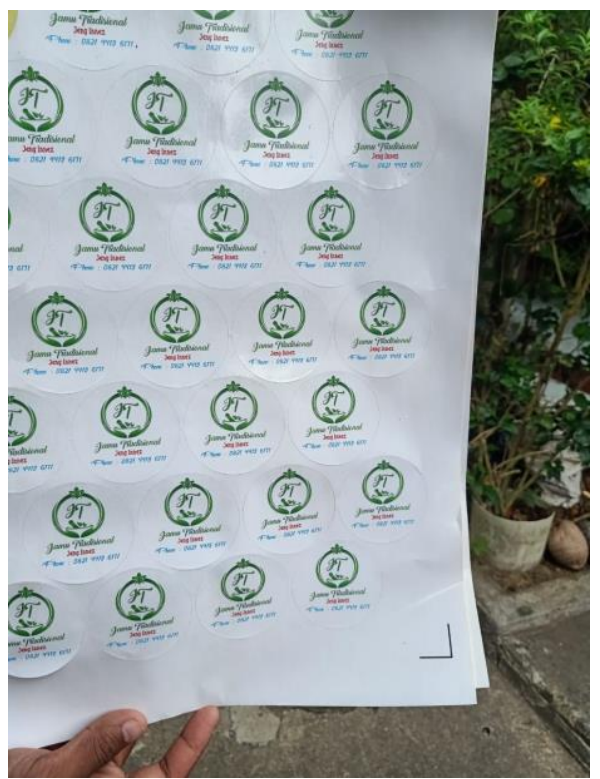

Gambar 7. Labelling

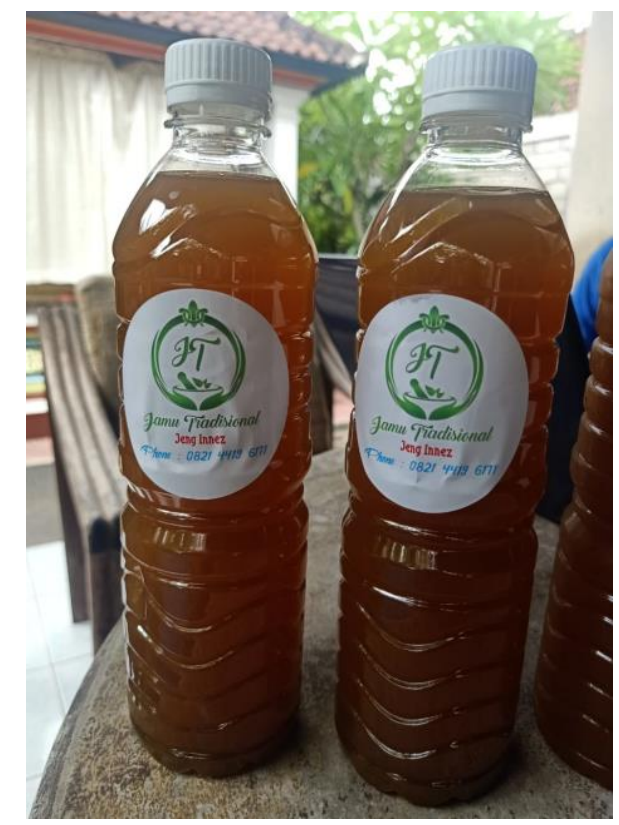

Gambar 8. Hasil Produk Dengan Label Pada Kemasan

4. Tahap akhir adalah evaluasi kegiatan pengabdian yang dilakukan untuk mengukur hasil pelaksanaan pengabdian kepada masyarakat yang telah dilakukan. Dalam kegiatan ini dilakukan evaluasi dari hasil pemberian alat bantu produksi dan penyuluhan serta pelatihan yang telah dilaksanakan. Tehnik evaluasi nya adalah dengan membuat laporan keuangan per 31 Desember 2019. Hasil laporan keuangan industri rumah tangga Jamu
Jeng Innez per tanggal 31 Desember 2019 menunjukkan profit sebesar $\mathrm{Rp}$ 4.016.000,00. Ini berarti terjadi kenaikan profit sebesar $335 \%$ dari pendapatan sebelumnya kurang lebih Rp 1.200.000,00. Sehingga melampaui dari target awal sebesar $100 \%$. Setelah diberikan bantuan alat produksi, mitra pengabdian mampu memproduksi jamu kurang lebih 30 liter yang pada awalnya hanya mampu memproduksi kurang lebih 9 liter perhari. Kemudian konsumen menjadi lebih tertarik dan yakin produk tersebut lebih higienis setelah diberikan botol kemasan dan label. Pemasarannya pun sudah menembus minimarket terdekat bahkan saat ini banyak permintaan untuk menjadi reseller. Hal ini juga didukung karena strategi pemasaran melalui media (facebook, WA dan Instagram). Rata-rata pesanan dari media pemasaran online 25 liter dan 5 liter pesanan secara manual perhari. Kemudian evaluasi berikutnya adalah memberikan kuisioner mengenai desain bentuk, desain warna, desain font logo kepada peserta. Untuk evaluasi terhadap kuisioner, penilaiannya adalah antara bagus/baik sampai memuaskan/ baik sekali. Peserta juga memberikan komentar bahwa penyuluhan dan pelatihan sangat bermanfaat bagi industri rumah tangga dan berharap kegiatan sejenis bisa dilakukan secara berkesinambungan di masa mendatang. Gambar laporan keuangan dan media pemasaran online ditunjukkan pada gambar 9,10,11 dan 12 dibawah ini : 


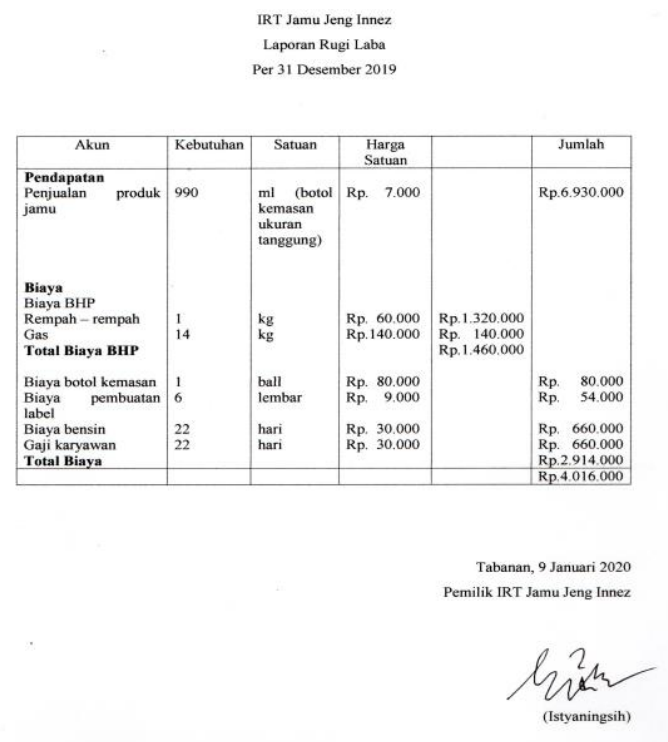

Gambar 9. Laporan Keuangan Per Tanggal 31 Desember 2019

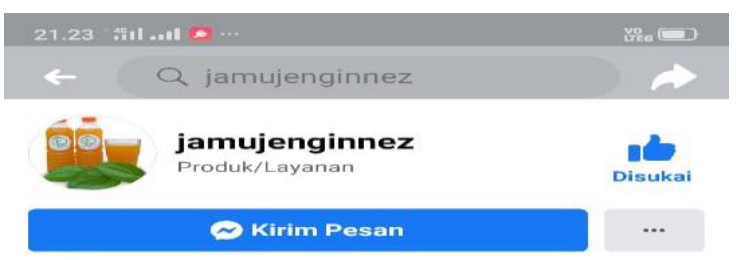

Dif Duija dan 122 lainnya menyukai ini

Beranda Postingan Ulasan Foto Komunitas
Tentang
Tanya Situs Web
$\Phi$ Kirim pertanyaan ini di Messenger.
$\Phi$ Krim Pesan

Lihat Semua

\section{Sarankan Editan}

Apakah halaman ini memiliki nomor telepon?

$$
\begin{array}{l|ll}
\text { Tidak } & \text { Tidak yakin } & \text { Ya }
\end{array}
$$

\section{F Transparansi Halaman} Facebook menampilkan informasi untuk membantu Anda
memahami tiinan Halaman dennan lehih haik I ihat tindakan

Gambar 10. Facebook Jamu Jeng Innez

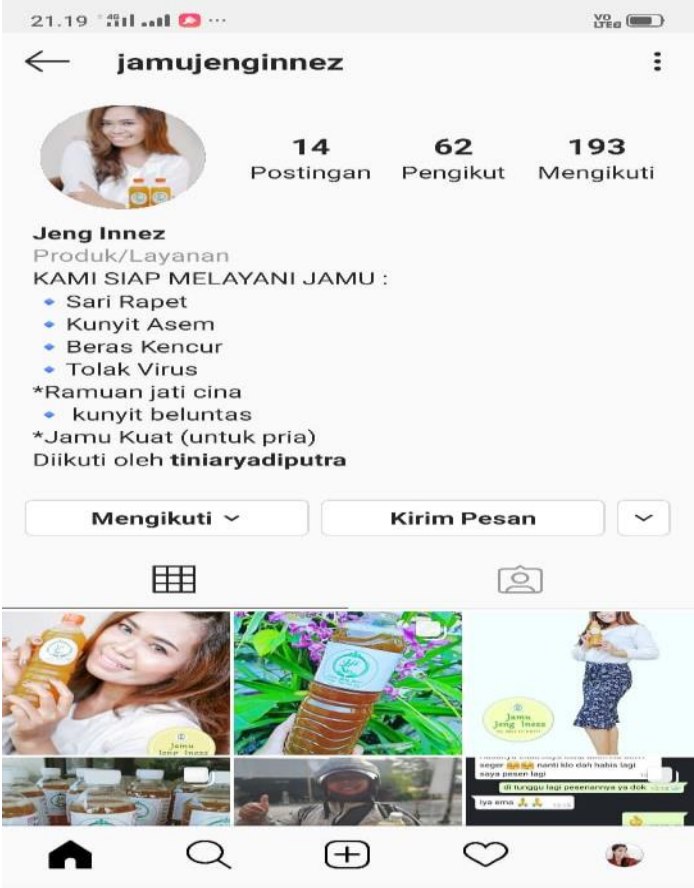

Gambar 11. Instagram Jamu Jeng Innez

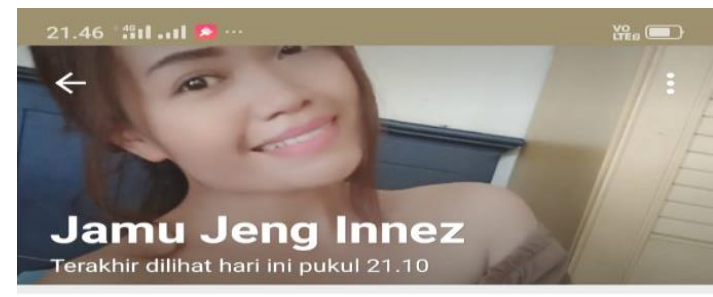

Media, tautan, dan dokumen

$1>$

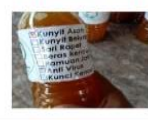

Bisukan notifikasi

Notifikasi khusus

Tampilkan media

Enkrips

Pesan yang dikirim ke chat ini dan panggilan diamankan dengan enkripsi end-to-end. Ketuk untuk memverifikasi.

Info dan nomor telepon

Gambar 12. WA Jamu Jeng Innez 


\section{SIMPULAN}

Berdasarkan analisis hasil pengabdian yang telah dilaksanakan maka dapat disimpulkan bahwa pemberian bantuan alat penggilingan rempah mampu meningkatkan hasil produksi dan peningkatan profit sebesar $335 \%$ melampaui dari target awal yaitu $100 \%$. Pemakaian botol kemasan dan labelling kemasan juga meningkatkan minat konsumen pada produk jamu, karena lebih higienis setelah menggunakan kemasan baru bukan botol bekas seperti sebelumnya. Dan daya tarik konsumen menjadi meningkat setelah penggunaan label yang menjadi ciri khas jamu Jeng Innez yang memiliki rasa yang nikmat dan segar karena diolah melalui pematangan dan proses pendinginan yang sempurna serta menggunakan bahan alami berkhasiat. Peserta pelatihan dan penyuluhan mampu menerima materi yang diberikan, sehingga tambahan ilmu tersebut dapat meningkatkan promosi untuk produk jamu. Penggunaan media pemasaran online (Facebook, WA dan Instagram) mampu menjangkau pemasaran yang lebih luas karena informasi yang diberikan kepada masyarakat lebih luas dan lengkap. Maanfaat lainnya adalah mitra pengabdian mulai bisa menata rapi arsip pembukuannya agar mudah untuk mengetahui kas masuk dan keluar. Dari hasil kegiatan yang telah dilakukan saat pengabdian masyarakat, terdapat masukan dari mitra pengabdian yaitu agar dapat dilakukan lagi kegiatan sejenis yang berkelanjutan sesuai dengan kebutuhan mitra pengabdian.

\section{UCAPAN TERIMA KASIH}

Puji syukur kami panjatkan kehadapan Tuhan Yang Maha Esa karena atas berkat dan rahmat-Nya, pengabdian kepada masyarakat ini dapat terlaksana dengan lancar dan sukses. Terima kasih kepada Institut Teknologi dan Bisnis Stikom Bali sebagai pihak yang mendukung terlaksananya pengabdian kepada masyarakat industri rumah tangga Jamu Jeng Innez. Dan terima kasih juga kepada Ibu Istyaningsih sebagai pemilik industri rumah tangga Jamu Jeng Innez yang telah memberikan ijin untuk melakukan pengabdian pada usahanya dan ucapan terima kasih juga untuk warga di Desa Tibubiu, Kecamatan Kerambitan, Kabupaten Tabanan, Bali yang selalu menyambut ramah setiap kedatangan tim pengabdian kami.

\section{DAFTAR PUSTAKA}

Akhina Z. 2019. Inilah Macam - macam Jamu Tradisional Khas Indonesia, 26 Juni 2019 [Online], www.goodnewsfromindonesia.id, diakses pada tanggal 28 September 2019.

Marinus, Angipora. 2002. Dasar-Dasar Pemasaran. Jakarta : Raja Grafindo Persada.

Philip Kotler, 2009. Marketing, Jilid I, Edisi 13, Jakarta, Erlangga, p : 200.

Philip Kotler, Kevin Lane Keller. 2007. Merancang Dan Mengelola Jaringan Dan Saluran Nilai, Manajemen Pemasaran, Edisi 12, Jilid 2, Jakarta, Indeks, $\mathrm{p}: 153$.

Philip Kotler, Kevin Lane Keller. 2009. Mendefinisikan Pemasaran Abad 21, Manajemen Pemasaran, Edisi 12, Jilid 1, Jakarta, Indeks, p : 23.

Tjiptono, Fandy.2008. Strategi Pemasaran. Yogyakarta: Andi.

Kalyanam dam, Kirthi dan Shelby McIntyre. 2002. 'The E-marketing Mix : A Contribution of the Etaling Wars', Journal of the Academy of Marketing Science, Vol.30, No.4, pp : 483-495. 